\title{
Retronasal olfactory testing in early diagnosed and suspected COVID-19 patients: a 7-week follow-up study
}

\author{
Bernhard Prem ${ }^{1} \cdot$ David Tianxiang Liu ${ }^{1} \cdot$ Gerold Besser $^{1} \cdot$ Bertold Renner $^{2,3} \cdot$ Christian Albert Mueller $^{1}$ (I)
}

Received: 1 February 2021 / Accepted: 14 April 2021 / Published online: 13 May 2021

(c) The Author(s) 2021

\begin{abstract}
Objectives Olfactory dysfunction (OD) constitutes a major symptom in Coronavirus Disease 2019 (COVID-19). Yet, most data on smell loss rely on the evaluation of orthonasal olfactory performance. Therefore, we aimed to assess retronasal olfactory function (ROF) over a period of several weeks in proven and suspected COVID-19 patients.

Methods One hundred and one subjects with suspected or laboratory-proven COVID-19 participated in this study. In patients with OD no longer than 4 weeks after initial symptom onset, ROF was measured with the 7-item Candy Smell Test ten times over 7 weeks.

Results Olfactory function was decreased in the investigated patients and remained decreased over the course of 7 weeks. One-way repeated-measures ANOVA revealed no significant difference of ROF between different measurement time points. However, self-assessment of smell and flavour improved significantly ( $p=0.013$ and $p=0.043$ ), but did not show complete recovery.

Conclusion The current investigation revealed significant improvements in subjective smell and flavour perception over the course of 7 weeks in proven and suspected COVID-19 patients suffering from acute OD. However, objectively measured ROF based on a screening test revealed no improvements within the same time period.
\end{abstract}

Keywords Anosmia $\cdot$ COVID-19 $\cdot$ Olfaction $\cdot$ Retronasal $\cdot$ Flavor

\section{Introduction}

The Coronavirus Disease 2019 (COVID-19) pandemic remains a challenging situation since the beginning of 2020 . Symptoms of infection with Severe-Acute-Respiratory-Syndrome Coronavirus-2 (SARS-CoV-2) are diverse and range from fever, cough, dyspnea, headache, fatigue, myalgia, diarrhea to olfactory dysfunction (OD) [1-4]. It is commonly acknowledged that OD can follow viral infections of the

Christian Albert Mueller

christian.a.mueller@meduniwien.ac.at

1 Department of Otorhinolaryngology, Head and Neck Surgery, Vienna General Hospital, Medical University of Vienna, 1090 Vienna, Austria

2 Institute of Experimental and Clinical Pharmacology and Toxicology, Friedrich-Alexander Universität Erlangen-Nürnberg, Erlangen, Germany

3 Medical Faculty Carl Gustav Carus, Institute of Clinical Pharmacology, Technische Universität Dresden, Dresden, Germany respiratory tract [5], detailed knowledge in the underlying mechanisms however is relatively sparse [6]. Beyond the overwhelming number of downsides, the current pandemic may hold the possibility of better understanding postviral OD [7].

At the beginning of the pandemic, OD was reported in 5\% of COVID-19 patients [8]. More recent studies revealed that overall more than two out of three COVID-19 patients in the US or Europe suffer from OD [9, 10], with a range from $19 \%$ up to $85 \%$ [11-13].

Different studies reported higher prevalences of selfassessed OD during the COVID-19 pandemic in general [3, 14], while others revealed subjective OD in proven SARSCoV-2 infected patients [11, 15, 16]. Until January 2021, only few studies confirmed OD by psychophysical olfactory testing. Moein et al. used the University of Pennsylvania Smell Identification Test (UPSIT) and showed that $98 \%$ of patients tested positive for COVID-19 suffer from different degrees of OD [17]. Using the identification subtest of Sniffin' Sticks, Lechien et al. reported OD in more than 70\% of SARS-CoV-2 infected patients [18]. All of these tests 
evaluate orthonasal olfactory function. However, retronasal olfactory testing has not been considered in COVID-19 patients, although retronasal olfaction represents a major contributor to flavour perception [19]. Furthermore, selfadministered smell tests should be advocated during home isolation due to suspected or active COVID-19 infection [20].

The aim of this study was to assess retronasal olfactory function during the course of suspected or proven infection with SARS-CoV-2 no longer than four weeks after symptom onset, using validated olfactory tests, suitable for self-administration.

\section{Materials and methods}

The present study was approved by the ethics committee of the Medical University of Vienna (EK-No.: 1339/2020) and conducted according to the guidelines of the declaration of Helsinki on biomedical research involving human subjects. Prior to participation, all subjects provided their written informed consent.

\section{Patients}

In this study, 101 patients (72f; 29m) with a mean age of 42.0 years (standard deviation (SD): 14.0; range 18-68 years) participated. In Austria, the first SARS-CoV-2 infections were recorded on the 25th of February 2020. We consequently included patients with subjectively novel OD and diagnosed or suspected with COVID-19 infection starting from this date. Press release [21] with information in several newspapers as well as invitational notices placed at the campus helped informing potential participants. Interested subjects contacted us via E-Mail, were informed by telephone and exclusion criteria (age below 18 or above 85 years, fructose intolerance or intolerance to sorbitol (component of the retronasal smell test), dysphagia, head/ neck-tumours, onset of $\mathrm{OD}$ prior to 25th of February 2020) were checked. In addition, we excluded patients who reported head trauma, sinonasal or neurological diseases, to include only suspected (and proven) COVID-19 patients.

Upon initial contact, patients were divided into two groups: Group 1 consisted of patients with onset of OD less than four weeks. Group 2 entailed patients with onset of OD longer than 4 weeks (Fig. 1). Patients of group 1 were tested repeatedly (see Fig. 1) to detect early recovery of olfactory performance [22].

\section{Questionnaires and tests sent by post}

Subjects received a package sent by post with a detailed description of self-administration of all chemosensory tests. Additional detailed instructions about the conduct of chemosensory tests were provided by telephone.
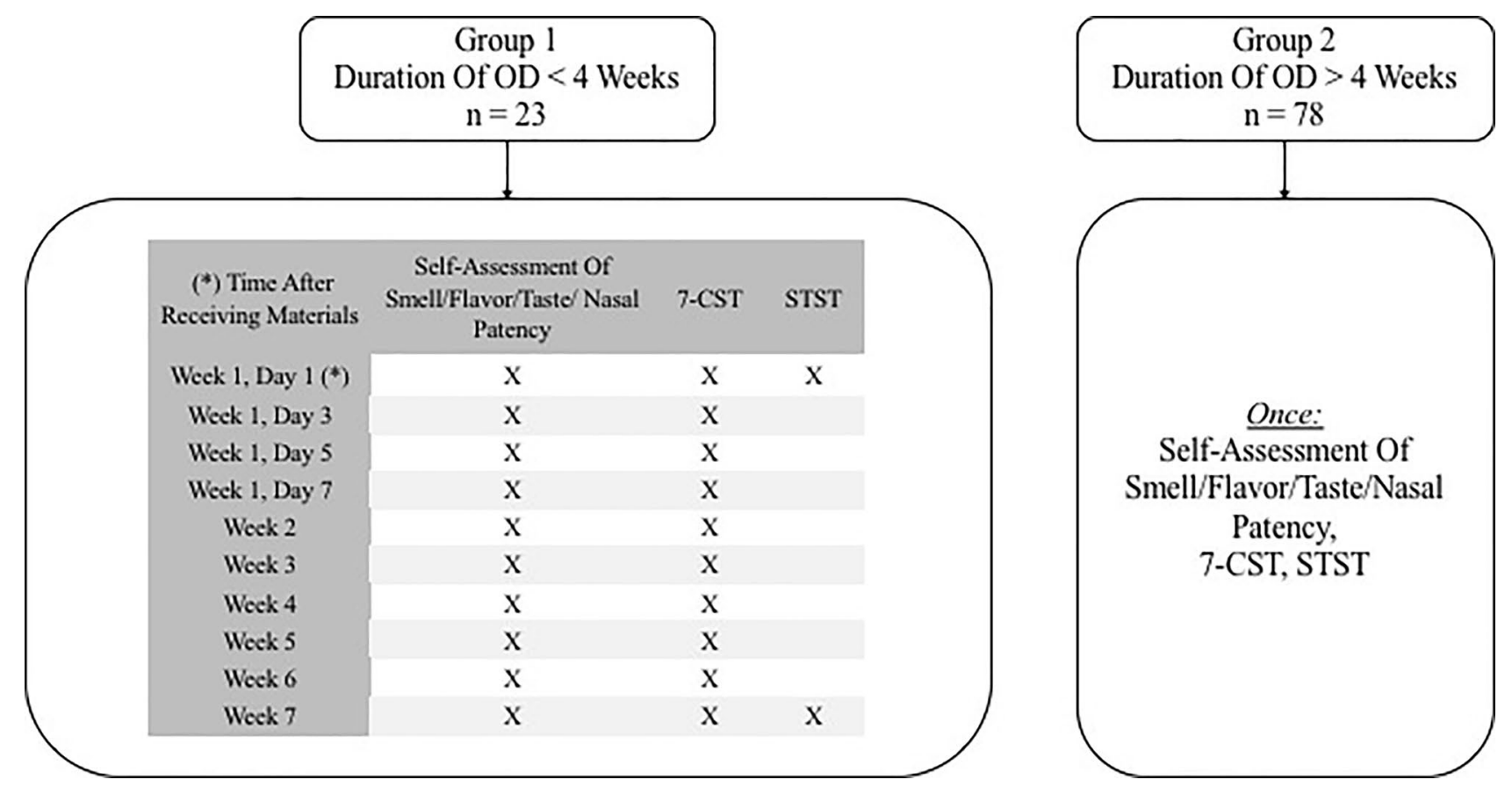

Fig. 1 Flowchart of the procedure according to group classification. OD olfactory dysfunction, 7-CST7-item Candy Smell Test, STSTSuprathreshold Taste Strips Test 
The package of group 1 contained general questions [age, gender, clinical symptoms), two questionnaires (Importance of Smell (IOS) and Questionnaire of Olfactory Disorders (QOD)] [23, 24], ten sets of a retronasal screening smell test (the 7-item-Candy-Smell-Test (7-CST), [25, 26]) and two sets of a Suprathreshold Taste Strips Test (STST) [27]. Patients were instructed to perform the 7-CST four times within the first week and once a week for another 6 weeks to record early regeneration of smell function [22]. STST was performed twice (together with the first and the last 7-CST).

Group 2 received a package containing the same general questions and questionnaires as well as one 7-CST and one STST.

After performing all chemosensory tests and questionnaires, completed materials were returned by mail.

\section{Self-assessment of smell, flavour and taste function, and nasal patency}

Investigated subjects were asked to rate their self-perceived chemosensory function of smell (SAS), flavour (SAF) and taste (SAT) on a scale from 1 (very bad) to 10 (very good) prior to every olfactory testing procedure. Upon inclusion, participants were informed about the chemosensory functions to distinguish smell, flavour and taste.

Furthermore, patients were also asked to rate SAS, SAF and SAT prior to COVID-19 infection and symptom onset based on the above-mentioned scale. Even though previous studies provided evidence that reduced olfactory function is not associated with obstruction of the nose in COVID-19 patients [11,28-30], we also assessed self-perceived nasal patency (SANP) prior to each psychophysical chemosensory testing.

\section{Chemosensory testing}

To evaluate retronasal olfactory function, we used the screening test (7-CST) of the Candy Smell Test (CST) [25]. Flavoured candies are placed separately on the tongue and have to be identified out of four different answers according to a forced-choice principle. In between the candies, the participants rinse the mouth with water or take a sip of water. The exact procedure is described elsewhere. [25] The CST is suitable for self-administration and postal distribution [26]. For the 7-CST seven candies have to be identified among 7 answers in a non-forced-choice procedure (thus, including the possibilities to choose "no flavour" or "undefinable"). Hence, the maximum obtainable score is 7 . In this setting 0 or 1 points on the 7-CST most likely represent anosmia, and scores of 5 or higher most likely represent normosmia, whereas scores between 2 and 4 most likely denote hyposmia [26].
The gustatory function was assessed in a screening fashion using the STST with the four highest concentrations of each taste (suprathreshold testing) [27]. Small paper strips soaked in different concentrations of taste solutions (e.g., sodium chloride, or saccharose) are placed on the tongue. After closing the mouth the tested subjects has to select one out of five answers (sweet, sour, salty, bitter, no taste). After each taste strip, the participants rinses the mouth with tap water. Besides four taste strips of different concentrations of each quality (sweet, sour, bitter, salty), two blanks complete a full set of 18 taste strips. Detailed procedural explanations are written elsewhere [27] and also self-administration has been advocated [31].

\section{Statistical analysis}

Statistical analysis and visualization of data were performed using IBM SPSS 26.0 (IBM Corp., Armonk, NY, USA) and Graph-Prism 8.4.3 (GraphPad Software, Inc., La Jolla, CA, USA). Normality of data distributions was analyzed based on histograms. One-way repeated-measures analysis of variance (ANOVA) was used for multiple group comparisons, followed by Tukey's post hoc tests. Pearson's correlation coefficient $(r)$ was used for bivariate correlations. A $p$ value $<0.05$ was considered for statistical significance.

\section{Results}

Nineteen patients $(82.6 \%)$ of group 1 (patients with OD no longer than four weeks) were tested positive for SARS$\mathrm{CoV}-2$ based either on polymerase chain reaction (PCR) or antibodies (AB) against SARS-CoV-2, four participants (17.4\%) were not tested initially during the acute phase of the disease. In 2 out of these 4 patients, no AB were detected either 163 or 186 days after the onset of OD. On average, participants from group 1 tested themselves 24 days (SD: 10.6) after the onset of OD. Besides OD, myalgia (56.5\%), cough $(52.2 \%)$ and fever (43.5\%) have been the most common symptoms within this group (Table 1).

In group 2 (patients with OD longer than 4 weeks), fifty-two subjects $(66.7 \%)$ were tested positive for SARSCoV-2 - either PCR or AB-and twenty-six participants (33.3\%) have not been tested for SARS-CoV-2 during the acute phase of disease. In 6 out of these 26 participants, no $\mathrm{AB}$ against SARS-CoV-2 were detected, on average, 186 days (range 157-221 days) after the onset of OD. The mean duration between the onset of OD and testing day of group 2 was 47 days (SD: 31.0$)$. Fever (42.3\%), cough (41.0\%), rhinitis $(39.7 \%)$ and myalgia (39.7\%) account for the most common symptoms besides OD (Table 2). To depict differences in the self-assessed and psychophysical chemosensory function of patients from group 1, we performed one-way 
Table 1 Descriptive statistics of Group 1

\begin{tabular}{|c|c|}
\hline \multicolumn{2}{|l|}{ Descriptive statistics } \\
\hline$N$ & 23 \\
\hline Gender & $\begin{array}{l}\text { Female: } 18 \\
\text { Male: } 5\end{array}$ \\
\hline Age (in years) & Mean: 41.2 (SD: 11.7; range: $24-57)$ \\
\hline $\begin{array}{l}\text { Duration of OD until first } \\
\text { testing (in days) }\end{array}$ & Mean: 23.9 (SD: 10.6; range: 5-44) \\
\hline \multirow[t]{3}{*}{ Tested $^{\mathrm{a}}$ for COVID-19 } & Not tested: 2 \\
\hline & Tested positive: 19 \\
\hline & Tested negative (AB): 2 \\
\hline \multirow[t]{3}{*}{ Smoker } & Never-smoker: 11 \\
\hline & Former smoker: 11 \\
\hline & Smoker: 1 \\
\hline BMI (in kg/m²) & Mean: 25.0 (SD: 3.4; range 19.5-34.0) \\
\hline \multicolumn{2}{|l|}{ Other symptoms } \\
\hline Cough & $12(52.2 \%)$ \\
\hline Sore throat & $9(39.1 \%)$ \\
\hline Fever & $10(43.5 \%)$ \\
\hline Dyspnea & $5(21.7 \%)$ \\
\hline Rhinitis & $6(26.1 \%)$ \\
\hline Myalgia & $13(56.5 \%)$ \\
\hline \multicolumn{2}{|l|}{ Self-assessment before OD } \\
\hline Smell & Mean: 9.6 (SD: 0.6; range 8-10) \\
\hline Flavour & Mean: 9.4 (SD: 0.8; range 8-10) \\
\hline Taste & Mean: 9.6 (SD: 0.7; range 8-10) \\
\hline Nasal patency & Mean: 9.0 (SD: 1.2; range 6-10) \\
\hline
\end{tabular}

$S D$ standard deviation, $B M I$ body mass index $\left(\mathrm{kg} / \mathrm{m}^{2}\right), O D$ olfactory dysfunction

${ }^{a}$ Using either polymerase-chained reaction (PCR) or antibodies (AB) against SARS-CoV-2

repeated-measures ANOVA (rm-ANOVA) with appropriate post hoc tests whenever applicable.

One-way rm-ANOVA for 7-CST results in course of 7 weeks revealed no significant differences $[F(4.64$, $85.51)=0.96 ; p=0.44$ ] (Fig. 2). Furthermore, the comparison of long-term results (at the beginning and the end of the 7 weeks observation period) of STST was not significantly different $(p=0.07)$.

One-way rm-ANOVA of SAS revealed significant differences across the observational period $[F(3.00$, $63.97)=26.59 ; p<0.002$ ] (Fig. 3). Tukey's post hoc test revealed significant improvement $(p=0.01)$ of SAS from the first (Test 1) to the last investigation (Test 10). Similarly, one-way rm-ANOVA of SAF also revealed significant differences $[F(3.59,76.46)=18.15 ; p<0.02]$ (Fig. 3). Tukey's post hoc test showed significant improvement of SAF between the first and the last test $(p=0.04)$. One-way rmANOVA of SAT in course of seven weeks revealed significant differences $[F(4.15,88.41)=13.08 ; p<0.001]$. Tukey's post hoc test showed significant deterioration of SAT after
Table 2 Descriptive statistics of Group 2

\begin{tabular}{|c|c|}
\hline \multicolumn{2}{|l|}{ Descriptive statistics } \\
\hline$N$ & 78 \\
\hline Gender & $\begin{array}{l}\text { Female: } 54 \\
\text { Male: } 24\end{array}$ \\
\hline Age (in years) & Mean: 42.2 (SD: 14.7; range 18-68) \\
\hline Tested $^{\mathrm{a}}$ for COVID-19 & $\begin{array}{l}\text { Not tested: } 20 \\
\text { Tested positive: } 52 \\
\text { Tested negative }(\mathrm{AB}): 6\end{array}$ \\
\hline Smoker & $\begin{array}{l}\text { Never-smoker: } 45 \\
\text { Former smoker: } 24 \\
\text { Smoker: } 9\end{array}$ \\
\hline BMI (in $\mathrm{kg} / \mathrm{m}^{2}$ ) & Mean: 24.3 (SD: 4.3 ; range 17.6-45.8) \\
\hline \multicolumn{2}{|l|}{ Other symptoms } \\
\hline Cough & $32(41.0 \%)$ \\
\hline Sore throat & $27(34.6 \%)$ \\
\hline Fever & $33(42.3 \%)$ \\
\hline Dyspnea & $19(24.4 \%)$ \\
\hline Rhinitis & $31(39.7 \%)$ \\
\hline Myalgia & $31(39.7 \%)$ \\
\hline \multicolumn{2}{|c|}{ Self-assessment before OD } \\
\hline Smell & Mean: 9.4 (SD: 1.2; range 8-10) \\
\hline Flavour & Mean: 9.3 (SD: 1.2 ; range $8-10$ ) \\
\hline Taste & Mean: 9.4 (SD: 1.3; range 8-10) \\
\hline Nasal patency & Mean: 9.0 (SD: 1.6; range 6-10) \\
\hline \multicolumn{2}{|l|}{ Chemosensory tests } \\
\hline 7-CST (in points) & Mean: 3.2 (SD: 2.0 ; range $0-7$ ) \\
\hline STST (in points) & Mean: 3.7 (SD: 0.7; range $1-4)$ \\
\hline
\end{tabular}

$S D$ standard deviation, $B M I$ body mass index $\left(\mathrm{kg} / \mathrm{m}^{2}\right), O D$ olfactory dysfunction

${ }^{\mathrm{a}}$ Using either polymerase chain reaction (PCR) or antibodies (AB) against SARS-CoV-2

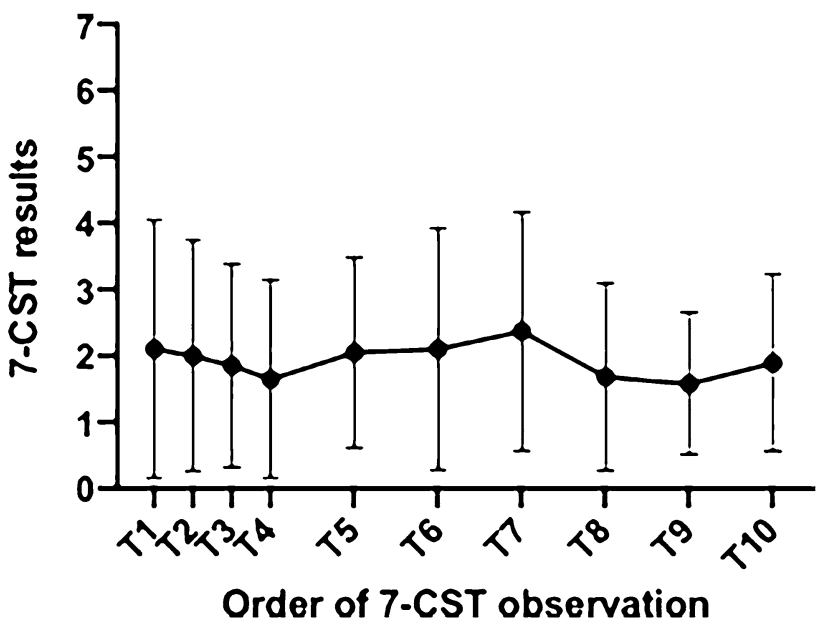

Fig. 2 Mean results ( \pm standard deviation) of 7-CST in course of 10 tests ( 7 weeks), Group $1(n=23)$. Tests $1-4$ : first week. Test 5: end of second week. Test 6: end of third week, etc. Test 10: end of seventh week. 7-CST7-item Candy Smell Test 

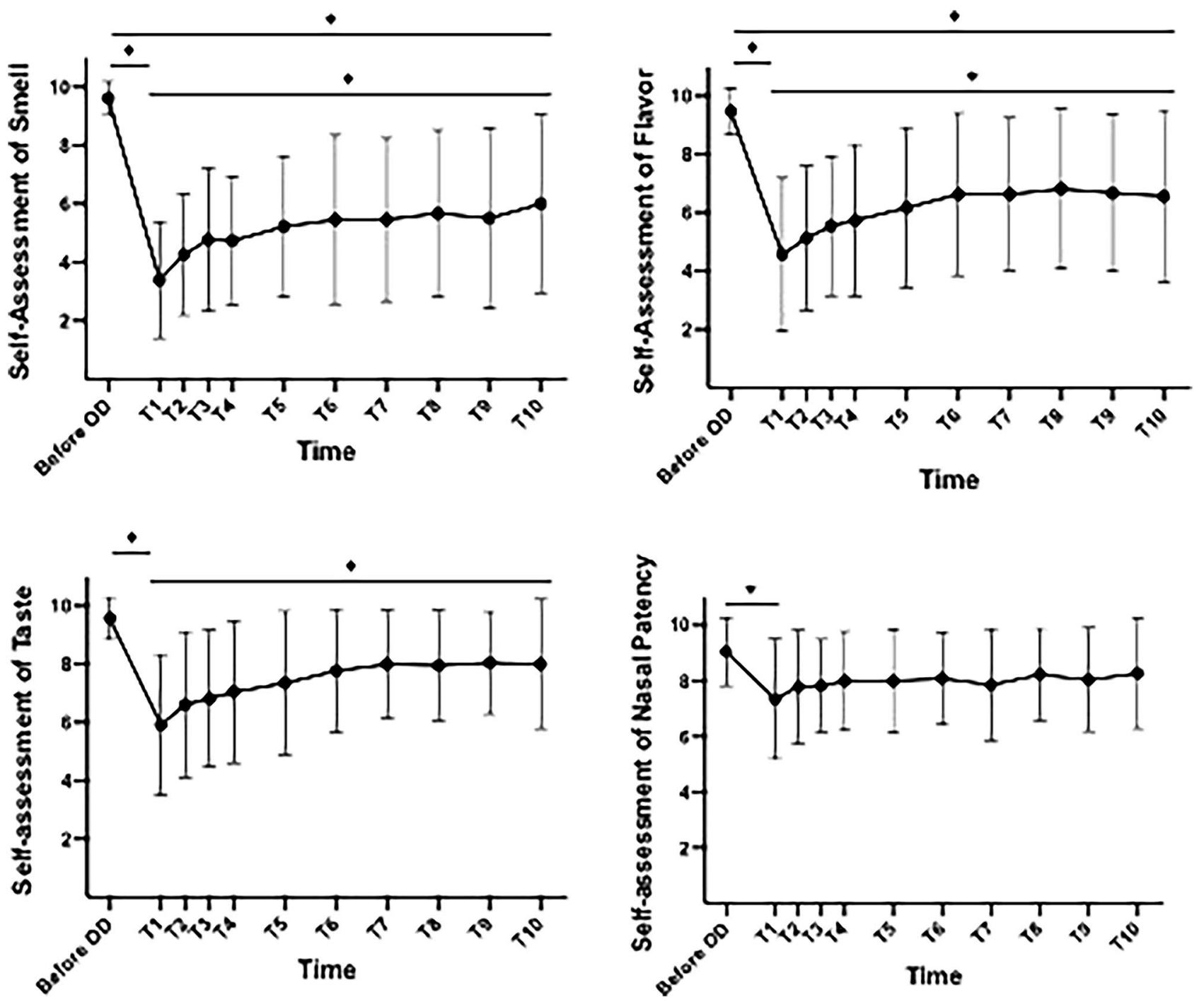

Fig. 3 Means ( \pm standard deviation) of self-perceived smell, flavour, and taste function and nasal patency on a scale from 1 (very bad) to 10 (very good)-before OD and during the course of psychophysical olfactory testing of group 1 . *Significant difference (if applicable,

marked only between before OD and T1, before OD and T10, or T1 and T10). $O D$ olfactory dysfunction, $T 1-T 10$ self-administered psychophysical olfactory testing $1-10$

the onset of OD. Nevertheless, subjective reconvalescence was only observed for taste function (Fig. 3).

In order to detect differences between proven $(n=71)$ and highly suspected $(n=30)$ SARS-CoV-2 infections, we compared subjective and objectively evaluated chemosensory function. Applying unpaired Student's $t$ test or Kolmogorov-Smirnov test between self-assessed (SAS, SAF, and SAT) and psychophysically tested (7-CST and STST) function of chemosensory function between these proven and suspected COVID-19 patients revealed no significant difference ( $p>0.05$, respectively).

To depict the relationship between self-assessed and psychophysical tested olfactory performance, we applied Pearson's correlation coefficient in group 1. Significant

correlations between 7-CST and SAS were seen at test 6 $\left(r_{23}=0.60 ; p=0.007\right)$, test $7\left(r_{23}=0.68 ; p=0.001\right)$, test 9 $\left(r_{23}=0.51 ; p=0.027\right)$ and test $10\left(r_{23}=0.63 ; p=0.002\right)$ of group 1 (Table 3 ). Significant correlation between 7-CST and SAF $\left(r_{23}=0.52 ; p=0.017\right)$ was observed only for the last test (Table 3). In group 2 we found significant correlations between 7-CST and SAS $\left(r_{78}=0.61 ; p<0.001\right)$, and between $7-\mathrm{CST}$ and SAF $\left(r_{78}=0.43 ; p<0.001\right)$. Furthermore, Pearson's correlation of the whole sample revealed a significant correlation between SAF and SAT $\left(r_{101}=0.73 ; p<0.001\right)$, as well as between SAS and SAT $\left(\mathrm{r}_{101}=0.48 ; \mathrm{p}<0.001\right)$, and between SAS and SAF $\left(r_{101}=0.65 ; p<0.001\right)$.

Results of STST and SAT at the beginning ( $r_{23}=0.49$; $p=0.018)$ and the end $\left(r_{23}=0.58 ; p=0.006\right)$ of the 7 weeks 
Table 3 Pearson's correlation $\left(r_{23}\right)$ between 7-CST results and either SAS or SAF during the course of psychophysical olfactory testing

\begin{tabular}{llrrrrrrrrrr}
\hline $\begin{array}{l}\text { Correlation between 7-CST } \\
\text { and either SAS or SAF }\end{array}$ & Test 1 & Test 2 & Test 3 & Test 4 & Test 5 & Test 6 & Test 7 & Test 8 & Test 9 & Test 10 \\
\hline Group 1 & & & & & & & & & & & \\
SAS & 0.35 & 0.18 & 0.05 & 0.27 & 0.15 & $0.60^{*}$ & $0.68^{*}$ & 0.36 & $0.51^{*}$ & $0.63^{*}$ \\
SAF & -0.15 & -0.18 & -0.14 & 0.10 & 0.27 & 0.38 & 0.30 & 0.05 & 0.17 & $0.52^{*}$ \\
\hline
\end{tabular}

7-CST7-item Candy Smell Test, SAS self-assessment of smell, SAF self-assessment of flavour

*Significant correlation $(p<0.05)$

period correlated significantly in group 1. Group 2 showed only weak correlation between STST results and SAT $\left(r_{78}=0.24 ; p=0.035\right)$.

The mean score of SANP before acute chemosensory dysfunction was $9.0(\mathrm{SD}=1.3)$ in group 1 . One-way rmANOVA $[F(4.69,100.8)=3.70 ; p=0.005]$ showed significant difference across observational period. Tukey's post hoc test revealed a significant difference only between SANP before acute onset of OD and SANP during the first test (Fig. 3). However, Pearson's correlation revealed no significant correlation between SANP and either SAS, SAF or 7-CST at any time.

Comparing SANP before OD and during test procedure in group 2 showed a significant difference $(p<0.001)$ after the onset of OD. A weak significant correlation between SANP and SAS was observed $\left(r_{78}=0.27 ; p=0.018\right)$; however, no significant correspondence between SANP and either SAF or 7-CST was found.

\section{Discussion}

In contrast to current publications evaluating orthonasal olfactory performance in COVID-19 patients, data regarding retronasal olfactory function and its course during acute phase of the disease are missing.

We could find the following main results: first, decreased olfactory function was found in the investigated patients measured by a validated retronasal smell test. Second, no significant differences in retronasal olfactory performance could be observed in course of seven weeks using a retronasal smell test made of candies. Third, decreased subjective smell and flavour perception increased during the observational period but did not reach normal levels. Fourth, in addition to reduced smell function, we observed a significant decrease in subjective gustatory function. And fifth, no considerable correlations between self-assessed nasal patency and either retronasal smell test results or subjective function of smell or flavour were found.

A few other studies evaluated follow-up assessment of OD by utilizing validated psychophysical olfactory tests [32-36]. Eighty-two patients suffering from OD due to
COVID-19 have been re-tested one or four weeks after the onset of OD using the University of Pennsylvania Smell Identification Test (UPSIT) [35]. Approximately 63\% were normosmic again. Nevertheless, in comparison to normative data, those patients still revealed worse olfactory function compared to the age- and gender-related mean of healthy population.

Another longitudinal study with a 2-month follow-up of patients suffering from OD, caused by SARS-CoV-2, revealed that 75 to $85 \%$ regained normal olfactory function applying SSI [36]. Five weeks after the onset of OD Le Bon et al. observed that $37 \%$ still suffer from OD by applying the complete "Sniffin' sticks" set [34]. Forty-six percent of all participants showed two months after the onset of OD pathological orthonasal olfactory function using the TDI [33]. However, due to the fact that flavour perception during food intake plays a major role in the individual quality of life, precise observation of retronasal olfactory function, especially during the COVID-19 pandemic, is crucial [37].

In the present study, no significant improvement of retronasal olfactory function within seven weeks was observed. With these results, we want to consider-in contrast to many other publications stating that OD lasts for only 4 weeks in most cases - that OD may last longer in more subjects than initially assumed. Nevertheless, patients reported subjective improvement of smell and flavour function. Due to this discrepancy, affected patients must be warned against hazardous situations — e.g. spoiled foodstuffs — and olfactory training should be considered in a medical consultation.

Cross-sectional observation (group 2) of retronasal olfactory performance showed 7-CST results out of the normal range in 58 out of 78 patients (74\%). This compares to other cross-sectional studies evaluating olfactory performance by orthonasal smell tests. The prevalences of OD in COVID-19 patients obtained by Sniffin' Sticks ranged from $37 \%$ five weeks after onset of OD [34], to 46\% after two months [33] and up to 71-83\% within the first month of OD [18]. Applying the UPSIT in Iran showed that even 98\% of COVID-19 patients suffered from OD [17]. Using the CCCRC, Vaira et al. revealed a prevalence of OD in $83 \%$ of SARS-CoV-2 patients [38]. 
In the present investigation, a screening test of retronasal olfactory function was advocated. Two other studies proved the applicability of short screening tests to detect reduced olfactory function in SARS-CoV-2-infected patients. Seventy-two percent of all self-reported OD in COVID-19 patients were proven by applying the 4-item pocket test [39]. Lima et al. revealed a significant difference in olfactory performance between COVID-19 patients with self-reported OD and a control group by utilizing the Quick Smell Identification Test [40]. The results of these two studies assume the applicability of short, psychophysical olfactory screening tests to evaluate olfactory performance. However, so far no other studies have evaluated retronasal olfactory function in COVID-19 patients.

Significant decrease in self-assessed smell and flavour perception in group 1 were reported after the onset of symptoms. During seven weeks of observation, self-assessment improved significantly. However, we could not objectify this subjective improvement with the 7-CST. One explanation may be that the 7-CST is a screening test and thus, slight changes in olfactory function remained undetected. Another reason may be the poor correlation between subjective and tested olfactory function in general [41, 42] and particular in COVID-19 patients [33]. However, significant differences between subjective function of smell and flavour before the onset of symptoms, on the first day of testing and after 7 weeks were observed. Thus, self-perceived function of smell and flavour improved significantly in course of disease, but still seemed to be significantly worse in comparison to selfassessment before the onset of symptoms, which we could confirm by the results of decreased smell tests.

Similar to Le Bon et al. [34], we observed acute decrease of subjective gustatory function during the onset of symptoms. Nevertheless, after 7 weeks of observation, there was no significant difference in taste function compared to the status before the onset of disease, revealing subjective reconvalescence of taste function. Repeated measures of tested taste function could not confirm this finding during the course of disease. However, due to the relatively short testing procedure (screening method), the test might not be able to detect subtle changes in taste performance. In summary, observing decreased self-assessed function of smell, flavour and taste all together in patients, support the suggestion of the close connection of the human chemical senses [43], or lead to the assumption that SARS-CoV-2 affects all chemosensory organs.

Due to the fact that not all patients provided proven infection with SARS-CoV-2 and, therefore, suspected COVID-19 patients might bias data, we compared those two groups. Neither self-assessed nor psychophysically evaluated chemosensory function showed significant differences between proven and suspected COVID-19 patients. Thus, complete data of the present study seem to be valid and comparable without obvious bias of the results. However, it seems to be feasible that sudden onset of smell loss in those patients also occurred due to infection with SARS-CoV-2.

During the course of observation within 7 weeks, we found no considerable correlation between subjective nasal patency and either SAS, SAF or 7-CST results of group 1. Thus, OD in SARS-CoV-2 might not be caused by impaired nasal patency. According to current studies, our results seem to be representative $[11,28-30]$.

\section{Conclusion}

The present investigation showed decreased olfactory function with no significant improvement of retronasal olfactory function using 7-CST in proven and suspected COVID-19 patients. However, subjective smell and flavour perception improved during the course of 7 weeks, but still differed significantly from before the onset of OD. In addition to current publications, we found no considerable correlation between subjective nasal patency and either (retronasal) olfactory function, or subjective assessment of smell or flavour perception in this study.

Acknowledgements We thank Frey\&Lau GmbH for providing aromas and S.Seyferth for professionally manufacturing candies.

Funding Open access funding provided by Medical University of Vienna. This project was supported by "Stiftungsfonds zur Foerderung der Bekaempfung der Tuberkulose und anderer Lungenkrankheiten" of the mayor of the city of Vienna.

\section{Declarations}

Conflict of interest The authors declare that there are no conflicts of interest regarding the publication of this paper.

Open Access This article is licensed under a Creative Commons Attribution 4.0 International License, which permits use, sharing, adaptation, distribution and reproduction in any medium or format, as long as you give appropriate credit to the original author(s) and the source, provide a link to the Creative Commons licence, and indicate if changes were made. The images or other third party material in this article are included in the article's Creative Commons licence, unless indicated otherwise in a credit line to the material. If material is not included in the article's Creative Commons licence and your intended use is not permitted by statutory regulation or exceeds the permitted use, you will need to obtain permission directly from the copyright holder. To view a copy of this licence, visit http://creativecommons.org/licenses/by/4.0/.

\section{References}

1. Rothan HA, Byrareddy SN (2020) The epidemiology and pathogenesis of coronavirus disease (COVID-19) outbreak. J Autoimmun 109:102433 
2. Jiang F, Deng L, Zhang L, Cai Y, Cheung CW, Xia Z (2020) Review of the Clinical Characteristics of Coronavirus Disease 2019 (COVID-19). J Gen Intern Med 35:1545-1549

3. Hopkins C, Surda P, Kumar N (2020) Presentation of new onset anosmia during the COVID-19 pandemic. Rhinology 58:295-298

4. Whitcroft KL, Hummel T (2020) Olfactory dysfunction in COVID-19: diagnosis and management. JAMA 323:2512-2514

5. Soler ZM, Patel ZM, Turner JH, Holbrook EH (2020) A primer on viral-associated olfactory loss in the era of COVID-19. Int Forum Allergy Rhinol 10:814-820

6. Hummel T, Whitcroft KL, Andrews P et al (2017) Position paper on olfactory dysfunction. Rhinol Suppl 54:1-30

7. Imam SA, Lao WP, Reddy P, Nguyen SA, Schlosser RJ (2020) Is SARS-CoV-2 (COVID-19) postviral olfactory dysfunction (PVOD) different from other PVOD? World J Otorhinolaryngol Head Neck Surg 6(1):S26-S32

8. Mao L, Wang M, Chen S et al (2020) Neurological manifestations of hospitalized patients with COVID-19 in Wuhan, China: a retrospective case series study. JAMA Neurol 77(6):683-690

9. Lechien JR, Chiesa-Estomba CM, De Siati DR et al (2020) Olfactory and gustatory dysfunctions as a clinical presentation of mild-to-moderate forms of the coronavirus disease (COVID19): a multicenter European study. Eur Arch Otorhinolaryngol 277:2251-2261

10. Chiesa-Estomba CM, Lechien JR, Radulesco T et al (2020) Patterns of smell recovery in 751 patients affected by the COVID-19 outbreak. Eur J Neurol 27:2318-2321

11. Klopfenstein T, Kadiane-Oussou NJ, Toko L et al (2020) Features of anosmia in COVID-19. Med Mal Infect 50:436-439

12. Kaye R, Chang CWD, Kazahaya K, Brereton J, Denneny JC 3rd (2020) COVID-19 anosmia reporting tool: initial findings. Otolaryngol Head Neck Surg 163:132-134

13. Vaira LA, Salzano G, Deiana G, De Riu G (2020) Anosmia and ageusia: common findings in COVID-19 patients. Laryngoscope 130:1787

14. Bagheri SHR, Asghari AM, Farhadi M et al (2020) Coincidence of COVID-19 epidemic and olfactory dysfunction outbreak. Med J Islam Repub Iran 34:62

15. Abalo-Lojo JM, Pouso-Diz JM, Gonzalez F (2020) Taste and smell dysfunction in COVID-19 patients. Ann Otol Rhinol Laryngol 129(10): 1041-1042

16. Carignan A, Valiquette L, Grenier $C$ et al (2020) Anosmia and dysgeusia associated with SARS-CoV-2 infection: an age-matched case-control study. CMAJ 192:E702-E707

17. Moein ST, Hashemian SMR, Mansourafshar B, Khorram-Tousi A, Tabarsi P, Doty RL (2020) Smell dysfunction: a biomarker for COVID-19. Int Forum Allergy Rhinol 10:944-950

18. Lechien JR, Cabaraux P, Chiesa-Estomba CM et al (2020) Psychophysical olfactory tests and detection of COVID-19 in patients with sudden onset olfactory dysfunction: a prospective study. Ear Nose Throat J 99(9):579-583

19. Liu DT, Besser G, Prem B et al (2020) Self-perceived taste and flavor perception: associations with quality of life in patients with olfactory loss. Otolaryngol Head Neck Surg. https://doi.org/10. $1177 / 0194599820965242$

20. Izquierdo-Dominguez A, Rojas-Lechuga MJ, Mullol J, Alobid I (2020) Olfactory dysfunction in the COVID-19 outbreak. J Investig Allergol Clini Immunol 30(5):317-326

21. Vienna MUV (2020) MedUni Wien erforscht Häufigkeit und Verlauf von Riechstörungen bei SARS-CoV-2-Infizierten. https:// www.meduniwien.ac.at/web/ueber-uns/news/detailseite/2020/ news-im-april-2020/meduni-wien-erforscht-haeufigkeit-und-verla uf-von-riechstoerungen-bei-sars-cov-2-infizierten/. Accessed 21 Mar 2021

22. Paderno A, Mattavelli D, Rampinelli V et al (2020) Olfactory and gustatory outcomes in COVID-19: a prospective evaluation in nonhospitalized subjects. Otolaryngol Head Neck Surg 163(6):1144-1149

23. Croy I, Buschhuter D, Seo HS, Negoias S, Hummel T (2010) Individual significance of olfaction: development of a questionnaire. Eur Arch Otorhinolaryngol 267:67-71

24. Frasnelli J, Hummel T (2005) Olfactory dysfunction and daily life. Eur Arch Otorhinolaryngol 262:231-235

25. Renner B, Mueller CA, Dreier J, Faulhaber S, Rascher W, Kobal G (2009) The candy smell test: a new test for retronasal olfactory performance. Laryngoscope 119:487-495

26. Besser G, Tianxiang Liu D, Prem B et al (2020) Retronasal olfactory testing using candies sent by post and for screening purposes: a feasibility study. Rhinology 58:218-225

27. Mueller CA, Kallert S, Renner B et al (2003) Quantitative assessment of gustatory function in a clinical context using impregnated "taste strips." Rhinology 41:2-6

28. Gane SB, Kelly C, Hopkins C (2020) Isolated sudden onset anosmia in COVID-19 infection. A novel syndrome? Rhinology 58(3):299-301

29. Iravani B, Arshamian A, Ravia A et al (2020) Relationship between odor intensity estimates and COVID-19 prevalence prediction in a Swedish population. Chem Senses. https://doi.org/10. 1093/chemse/bjaa034

30. Lehrich BM, Goshtasbi K, Raad RA et al (2020) Aggregate prevalence of chemosensory and sinonasal dysfunction in SARS$\mathrm{CoV}-2$ and related coronaviruses. Otolaryngol-Head Neck Surg 163(1):156-161

31. Wolf A, Varga L, Wittibschlager L, Renner B, Mueller CA (2016) A self-administered test of taste function using "Taste Strips." Int Forum Allergy Rhinol 6:362-366

32. Iannuzzi L, Salzo AE, Angarano G et al (2020) Gaining back what is lost: recovering the sense of smell in mild to moderate patients after COVID-19. Chem Senses 45(9):875-881

33. Otte MS, Eckel HNC, Poluschkin L, Klussmann JP, Luers JC (2020) Olfactory dysfunction in patients after recovering from COVID-19. Acta Oto-Laryngol 140(12):1032-1035

34. Le Bon SD, Pisarski N, Verbeke J et al (2020) Psychophysical evaluation of chemosensory functions 5 weeks after olfactory loss due to COVID-19: a prospective cohort study on 72 patients. Eur Arch Otorhinolaryngol. https://doi.org/10.1007/ s00405-020-06267-2

35. Moein ST, Hashemian SM, Tabarsi P, Doty RL (2020) Prevalence and reversibility of smell dysfunction measured psychophysically in a cohort of COVID-19 patients. Int Forum Allergy Rhinol 10(10):1127-1135

36. Lechien J, Chiesa-Estomba C, Beckers E et al (2021) Prevalence and recovery of olfactory dysfunction in 1,363 patients with coronavirus disease 2019: a multicenter longitudinal study. J Intern Med. https://doi.org/10.1111/joim.13209

37. Negoias S, Meves B, Zang Y, Haehner A, Hummel T (2020) Characteristics of olfactory disorder with and without reported flavor loss. Laryngoscope 130(12):2869-2873

38. Vaira LA, Deiana G, Fois AG et al (2020) Objective evaluation of anosmia and ageusia in COVID-19 patients: single-center experience on 72 cases. Head Neck 42(6):1252-1258

39. Hintschich CA, Wenzel JJ, Hummel T et al (2020) Psychophysical tests reveal impaired olfaction but preserved gustation in COVID19 patients. Int Forum Allergy Rhinol 10:1105-1107

40. Lima MA, Silva MTT, Oliveira RV et al (2020) Smell dysfunction in COVID-19 patients: more than a yes-no question. J Neurol Sci 418:117107

41. Welge-Luessen A, Hummel T, Stojan T, Wolfensberger M (2018) What is the correlation between ratings and measures of olfactory function in patients with olfactory loss? Am J Rhinol 19:567-571 
42. Liu DT, Besser G, Prem B et al (2020) Association between orthonasal olfaction and chemosensory perception in patients with smell loss. Laryngoscope 130:2213-2219

43. Migneault-Bouchard C, Hsieh JW, Hugentobler M, Frasnelli J, Landis BN (2020) Chemosensory decrease in different forms of olfactory dysfunction. J Neurol 267:138-143
Publisher's Note Springer Nature remains neutral with regard to jurisdictional claims in published maps and institutional affiliations. 